\title{
New Insight Regarding the Relationship between Enantioselective Toxicity Difference and Enantiomeric Toxicity Interaction from Chiral Ionic Liquids
}

\author{
Huilin Ge ${ }^{1,2, *}$, Min Zhou ${ }^{1,2}$, Daizhu Lv ${ }^{1}$, Mingyue Wang ${ }^{1, *}$, Cunzhu Dong ${ }^{2}$, Yao Wan ${ }^{1}$, \\ Zhenshan Zhang ${ }^{1}$ and Suru Wang ${ }^{1}$ \\ 1 Hainan Key Laboratory of Tropical Fruit and Vegetable Products Quality and Safety, Analysis and Testing \\ Center, Chinese Academy of Tropical Agricultural Sciences, Haikou 571101, China; \\ zhoumin05@yeah.net (M.Z.); ldz162000@126.com (D.L.); wanyao_analyt@163.com (Y.W.); \\ zhenshanzhang@163.com (Z.Z.); wsr28412466@163.com (S.W.) \\ 2 College of Plant Protection, Hainan University, Haikou 570228, China; czd@hainu.edu.cn \\ * Correspondence: huilinge@126.com (H.G.); hkwmy0815@163.com (M.W.); \\ Tel.: +86-898-6689-5011 (H.G.); +86-898-6689-5002 (M.W.)
}

Received: 12 November 2019; Accepted: 4 December 2019; Published: 6 December 2019

\begin{abstract}
Chirality is an important property of molecules. The study of biological activity and toxicity of chiral molecules has important theoretical and practical significance for toxicology, pharmacology, and environmental science. The toxicological significance of chiral ionic liquids (ILs) has not been well revealed. In the present study, the enantiomeric joint toxicities of four pairs of chiral ILs 1-alkyl-3-methylimidazolium lactate to Allivibrio fischeri were systematically investigated by using a comprehensive approach including the co-toxicity coefficient (CTC) integrated with confidence interval (CI) method (CTCICI), concentration-response curve (CRC), and isobole analysis. The direct equipartition ray (EquRay) design was used to design five binary mixtures of enantiomers according to molar ratios of 1:5, 2:4, 3:3, 4:2, and 5:1. The toxicities of chiral ILs and their mixtures were determined using the microplate toxicity analysis (MTA) method. Concentration addition (CA) and independent action (IA) were used as the additive reference models to construct the predicted CRC and isobole of mixtures. On the whole, there was an enantioselective toxicity difference between [BMIM]D-Lac and [BMIM]L-Lac, and [HMIM]D-Lac and [HMIM]L-Lac, while no enantioselective toxicity difference was observed for [EMIM]D-Lac and [EMIM]L-Lac, and [OMIM]D-Lac and [OMIM]L-Lac. Thereinto, the enantiomer mixtures of [BMIM]D-Lac and [BMIM]L-Lac, and [HMIM]D-Lac and [HMIM]L-Lac presented antagonistic action, and the enantiomer mixtures of [EMIM]D-Lac and [EMIM]L-Lac, and [OMIM]D-Lac and [OMIM]L-Lac overall presented additive action. Moreover, the greatest antagonistic toxicity interaction occurred at the equimolar ratio of enantiomers. Based on these results, we proposed two hypotheses, (1) chiral molecules with enantioselective toxicity difference tended to produce toxicity interactions, (2) the highest or lowest toxicity was usually at the equimolar ratio and its adjacent ratio for the enantiomer mixture. These hypotheses will need to be further validated by other enantiomer mixtures.
\end{abstract}

Keywords: chiral ionic liquids; Aliivibrio fischeri; isobole; mixture toxicity; concentration addition; independent action; co-toxicity coefficient; antagonism

\section{Introduction}

Chirality is the geometric characteristic of a molecule being not superimposable on its mirror image formed by inversion through a point by pure rotation and translation. Chiral molecules with a single chiral center have two stereochemical arrangements, which have identical physicochemical properties, 
but can differ in biological activity and toxicity [1]. Biological systems are also chiral environments composed of biological macromolecules (such as enzymes), which interact differentially with chiral small molecules. Chiral enantiomers enter the organism and are identified and matched by the chiral environment as different molecules. Enantiomers usually have stereoselectivity in pharmacokinetics, pharmacodynamics, and drug metabolism (PK/PD/DM), and toxicology [2].

The pharmacology and toxicology significances of chiral drugs and chiral pesticides have been widely recognized. For example, the stereoselective potencies and relative toxicities of coniine enantiomers and racemate were evaluated to human rhabdomyoma cells and mice [3]. The efficacy, toxicity, pharmacokinetics, and in vitro metabolism of the enantiomers and racemate of ifosfamide were studied in mice [4]. The stereoselective metabolism, pharmacokinetics, pharmacodynamics, and toxicity of vasicine enantiomers were studied in vitro and in vivo [5]. Asymmetric dimethylarginine and its enantiomer symmetric dimethylarginine were associated with chronic kidney disease and other cardiovascular risks [6]. The enantiomers of naproxen, ibuprofen, ketoprofen, and flurbiprofen were evaluated in bioassays with bacteria, algae, and fish cells [7]. The enantioselective toxicity difference was observed for dinotefuran, $S$-dinotefuran was 41.1 to 128.4 fold more toxic than $R$-dinotefuran to honeybee, whereas $R$-dinotefuran exhibited comparative insecticidal activities (1.7-2.4 times) compared to the racemic mixtures [8]. Systematic assessments for four stereoisomers of propiconazole with two chiral centers were performed, including absolute configuration, stereoselective bioactivity, and toxicity [9]. The enantioselectivity of isocarbophos were studied in rice cultivation, including bioactivity, toxicity, and environmental fate [10]. The activity, toxicity, molecular docking, and environmental effects of three pairs of imidazolinone herbicides enantiomers were studied [11]. Chiral herbicide dichlorprop can induce the chiral macroaggregates structural change of light-harvesting chlorophyll a/b pigment-protein complexes, which was associated with the enantioselective toxicity to Scnedesmus obliquus [12].

Although enantioselective toxicity difference of chiral pesticides has been received fundamental understanding during the past few decades, how coexisting enantiomers interacting with each other during their toxicity action remained largely unknown. Various methods have tried to understand the toxic interaction between enantiomers. Metabolomics were used to study the metabolic perturbations and toxic effects of rac-metalaxyl and metalaxyl-M in mice using NMR and UPLC-MS/MS [13]. Molecular docking methods based on computational chemistry were used to compare the binding affinities of enantiomer pairs to the protein target [14]. The toxic unit (TU) method was employed to evaluate the joint additive toxicity of isocarbophos enantiomer to Daphnia magna [15]. Isobole analysis was used to evaluate the synergistic action between the enantiomers of tramadol [16]. Although both TU and isobole models can be attributed to the CA model, CA and IA as the mainstream additive reference models for the prediction and assessment of mixture toxicity at present [17], have not been widely and deeply applied in enantiomer combined toxicity studies. In the present study, the methods of CA, IA, isobole, and CTCICI [18] were used to comprehensively analyze the toxic interaction of enantiomer mixtures.

ILs are a group of organic salts that are liquid at room temperature [19]. The application areas of ILs included catalysis, extraction, synthesis, dissolution, food science, and so on [20]. With the development of industry and the needs of the society, chiral ILs have also achieved considerable development [21]. Chiral ILs have been used in optical resolution, asymmetric synthesis, chiral stationary phase in chromatography, and chiral selectors [22]. To date, most of the reported chiral ILs were those based on chiral cations, only a very limited number of chiral ILs contained chiral anions [23]. The toxicological significance of chiral ILs has not been well revealed. Although, many studies have reported the biological toxicities of ILs to enzymes, bacteria, algae, mammalian cells, plants, invertebrates, and vertebrates [24-30], However, most of these ILs studied were non-chiral. Chiral ILs may also exhibit enantioselective toxicity difference. For example, for 1-alkyl-3-methylimidazolium lactate, there was a distinct difference between the toxicities of [EMIM]L-(+)-Lac and [EMIM]D-(-)-Lac toward green algae Scenedesmus obliquus and Euglena gracilis [31]. Chiral ILs 1-alkyl-3-methyl 
imidazolium tartrate can cause enantioselective oxidative stress to Scenedesmus obliquus, and the toxicity of [RMIM]L-(+)-tartrate treatment was greater than [RMIM]D-(-)-tartrate with enantioselectivity [32]. However, the toxicity interaction of chiral ILs enantiomers was still not entirely clear and has not been systematically studied up to now.

In the present study, we selected four pairs of chiral ILs composed of imidazolium cation and lactate anion as the enantiomer components. They were [EMIM]D-Lac and [EMIM]L-Lac, [BMIM]D-Lac and [BMIM]L-Lac, [HMIM]D-Lac and [HMIM]L-Lac, and [OMIM]D-Lac and [OMIM]L-Lac. Their specific information is shown in the section of Materials and Methods. Among them, the imidazole cations were not chiral. While lactate anion has two enantiomers of L-lactate and D-lactate, and the human body can only metabolize the L-lactic acid [33]. We want to know how coexisting chiral ILs enantiomers interact with each other in the toxicity. Such considerations prompt us to initiate this study, which aims (1) to investigate the enantioselective toxicity difference for chiral ILs, (2) to investigate the enantiomeric toxicity interaction of chiral ILs, and (3) to determine whether there was some relationship between enantioselective toxicity difference and enantiomeric toxicity interaction.

\section{Results and Discussion}

\subsection{Single Enantiomer Toxicity}

All of the studied enantiomers inhibited Allivibrio fischeri (AVF) in a concentration-dependent manner, with log-sigmoidal CRC for the four pairs of chiral ILs shown in Figure 1. The concentration of the stock solutions $\left(C_{0}\right)$ and following diluted solutions $\left(C_{1}-C_{11}\right)$ of chiral ILs and their mixtures were shown in Table S1. The regression models and the estimated parameters of the toxicity of single enantiomer to AVF are summarized in Table 1. The CRCs can be fitted by the two-parameter Weibull function with RMSE $<0.09$ and $R^{2}>0.91$. The variability of the blank control in the test was controlled within $\pm 20 \%$. The indicators of effect concentration $\mathrm{EC}_{80}, \mathrm{EC}_{50}$, and $\mathrm{EC}_{30}$ are shown in Table 1. According to these indicators, the toxicity order of single enantiomers was OL $\geq \mathrm{OD}>\mathrm{HL}$ $>\mathrm{HD}>\mathrm{BD}>\mathrm{BL}>\mathrm{EL} \geq \mathrm{ED}$. With the increase of the number of carbon atoms in the alkyl chains of the imidazolium cations, the toxicity of chiral ILs increased gradually. The $\mathrm{EC}_{50}$ of EL was 143 times that of $\mathrm{OL}$, and the $\mathrm{EC}_{50}$ of ED was 137 times that of OD. Stock et al. also reported that ILs with long alkyl chains showed higher AVF inhibitive toxicity [34]. 

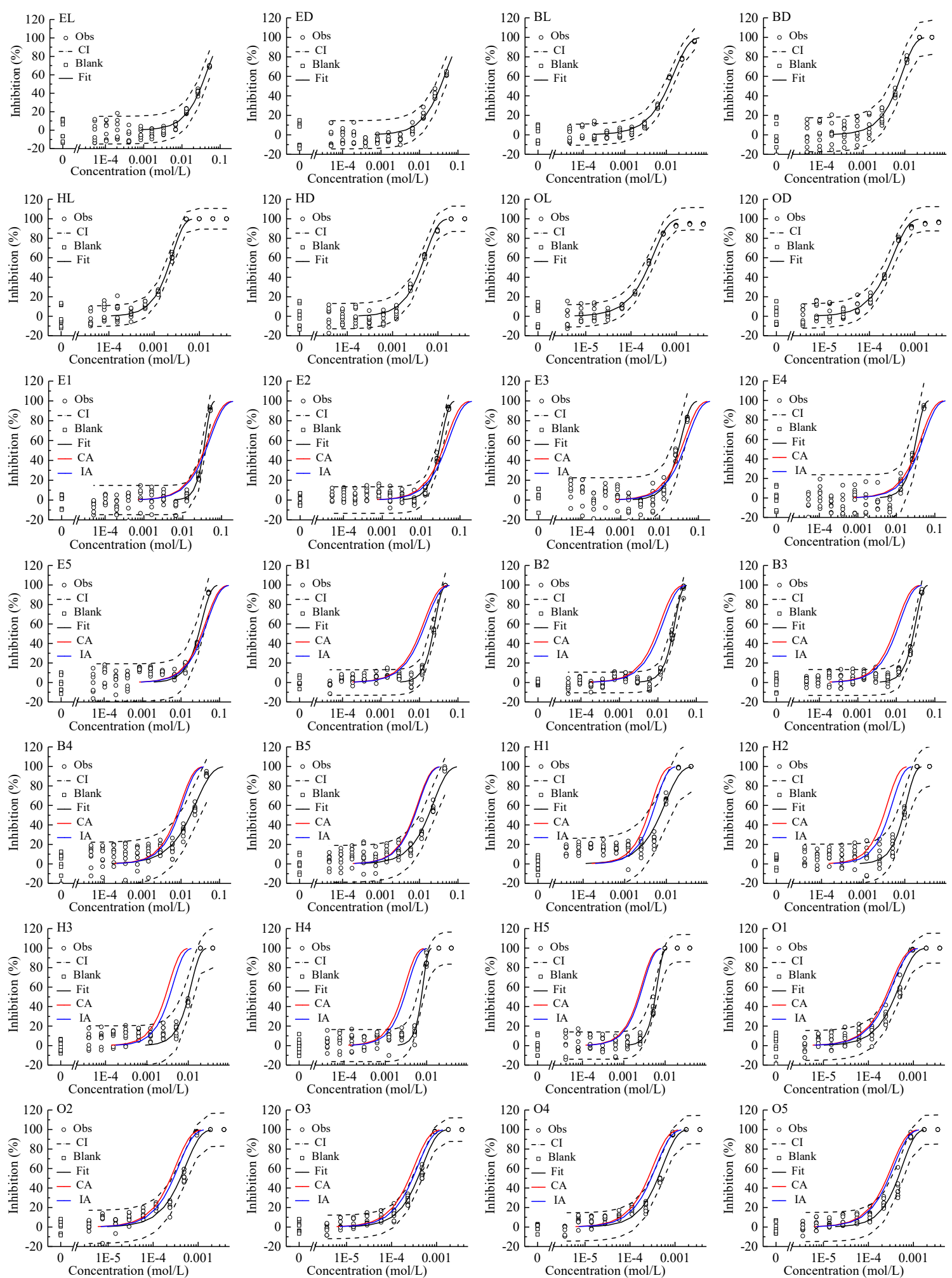

Figure 1. Concentration-response curves of single enantiomer and their mixtures of four pairs of chiral ionic liquids inhibiting Allivibrio fischeri. Note: Square: blank control; Circle: observed data; Black dashed line: confidence interval; Black solid line: Weibull model fit; Red line: Concentration addition (CA) prediction; Blue line: independent action (IA) prediction. 
Table 1. Concentration-response model of single enantiomer and their binary mixtures of four pairs of chiral ionic liquids inhibiting Allivibrio fischeri and related parameters.

\begin{tabular}{|c|c|c|c|c|c|c|c|c|c|}
\hline Toxicants & Molar Ratio & $\mathrm{C}_{0}$ & $a$ & $b$ & $R^{2}$ & RMSE & $\mathrm{EC}_{30}$ & $\mathrm{EC}_{50}$ & $\mathrm{EC}_{80}$ \\
\hline EL & & $1.05 \times 10^{-1}$ & 4.178 & 3.093 & 0.913 & 0.075 & $2.07 \times 10^{-2}$ & $3.39 \times 10^{-2}$ & $6.35 \times 10^{-2}$ \\
\hline ED & & $1.01 \times 10^{-1}$ & 3.821 & 2.890 & 0.910 & 0.072 & $2.09 \times 10^{-2}$ & $3.56 \times 10^{-2}$ & $6.96 \times 10^{-2}$ \\
\hline $\mathrm{BL}$ & & $9.51 \times 10^{-2}$ & 5.020 & 2.759 & 0.978 & 0.054 & $6.41 \times 10^{-3}$ & $1.12 \times 10^{-2}$ & $2.25 \times 10^{-2}$ \\
\hline $\mathrm{BD}$ & & $9.00 \times 10^{-2}$ & 6.596 & 3.196 & 0.958 & 0.088 & $4.11 \times 10^{-3}$ & $6.63 \times 10^{-3}$ & $1.22 \times 10^{-2}$ \\
\hline $\mathrm{HL}$ & & $7.92 \times 10^{-2}$ & 10.19 & 3.925 & 0.988 & 0.053 & $1.38 \times 10^{-3}$ & $2.04 \times 10^{-3}$ & $3.35 \times 10^{-3}$ \\
\hline HD & & $7.83 \times 10^{-2}$ & 8.155 & 3.592 & 0.980 & 0.065 & $2.77 \times 10^{-3}$ & $4.24 \times 10^{-3}$ & $7.28 \times 10^{-3}$ \\
\hline $\mathrm{OL}$ & & $7.91 \times 10^{-3}$ & 10.70 & 3.053 & 0.983 & 0.057 & $1.44 \times 10^{-4}$ & $2.37 \times 10^{-4}$ & $4.48 \times 10^{-4}$ \\
\hline OD & & $6.79 \times 10^{-3}$ & 10.68 & 3.081 & 0.979 & 0.063 & $1.58 \times 10^{-4}$ & $2.60 \times 10^{-4}$ & $4.88 \times 10^{-4}$ \\
\hline E1 & 1:5 (EL:ED) & $1.02 \times 10^{-1}$ & 10.26 & 7.255 & 0.938 & 0.074 & $2.78 \times 10^{-2}$ & $3.43 \times 10^{-2}$ & $4.48 \times 10^{-2}$ \\
\hline E2 & 2:4 (EL:ED) & $1.02 \times 10^{-1}$ & 7.783 & 5.290 & 0.946 & 0.067 & $2.16 \times 10^{-2}$ & $2.88 \times 10^{-2}$ & $4.16 \times 10^{-2}$ \\
\hline E3 & $3: 3$ (EL:ED) & $1.03 \times 10^{-1}$ & 6.114 & 4.253 & 0.850 & 0.113 & $2.09 \times 10^{-2}$ & $2.99 \times 10^{-2}$ & $4.72 \times 10^{-2}$ \\
\hline $\mathrm{E} 4$ & $4: 2$ (EL:ED) & $1.04 \times 10^{-1}$ & 8.181 & 5.575 & 0.876 & 0.119 & $2.23 \times 10^{-2}$ & $2.93 \times 10^{-2}$ & $4.15 \times 10^{-2}$ \\
\hline E5 & 5:1 (EL:ED) & $1.04 \times 10^{-1}$ & 6.210 & 4.264 & 0.882 & 0.096 & $2.00 \times 10^{-2}$ & $2.87 \times 10^{-2}$ & $4.52 \times 10^{-2}$ \\
\hline B1 & 1:5 (BD:BL) & $9.42 \times 10^{-2}$ & 9.308 & 5.854 & 0.960 & 0.065 & $1.71 \times 10^{-2}$ & $2.23 \times 10^{-2}$ & $3.10 \times 10^{-2}$ \\
\hline B2 & 2:4 (BD:BL) & $9.33 \times 10^{-2}$ & 8.839 & 5.690 & 0.972 & 0.053 & $1.84 \times 10^{-2}$ & $2.41 \times 10^{-2}$ & $3.39 \times 10^{-2}$ \\
\hline B3 & $3: 3$ (BD:BL) & $9.25 \times 10^{-2}$ & 8.463 & 5.682 & 0.945 & 0.066 & $2.13 \times 10^{-2}$ & $2.79 \times 10^{-2}$ & $3.93 \times 10^{-2}$ \\
\hline $\mathrm{B} 4$ & $4: 2$ (BD:BL) & $9.16 \times 10^{-2}$ & 3.885 & 2.422 & 0.855 & 0.111 & $9.34 \times 10^{-3}$ & $1.76 \times 10^{-2}$ & $3.91 \times 10^{-2}$ \\
\hline B5 & $5: 1$ (BD:BL) & $9.08 \times 10^{-2}$ & 4.562 & 2.796 & 0.906 & 0.095 & $9.99 \times 10^{-3}$ & $1.73 \times 10^{-2}$ & $3.46 \times 10^{-2}$ \\
\hline $\mathrm{H} 1$ & 1:5 (HL:HD) & $7.84 \times 10^{-2}$ & 5.580 & 2.766 & 0.869 & 0.130 & $4.07 \times 10^{-3}$ & $7.08 \times 10^{-3}$ & $1.43 \times 10^{-2}$ \\
\hline $\mathrm{H} 2$ & 2:4 (HL:HD) & $7.86 \times 10^{-2}$ & 9.297 & 4.748 & 0.935 & 0.102 & $6.68 \times 10^{-3}$ & $9.22 \times 10^{-3}$ & $1.39 \times 10^{-2}$ \\
\hline H3 & 3:3 (HL:HD) & $7.87 \times 10^{-2}$ & 9.164 & 4.766 & 0.927 & 0.102 & $7.26 \times 10^{-3}$ & $1.00 \times 10^{-2}$ & $1.50 \times 10^{-2}$ \\
\hline $\mathrm{H} 4$ & $4: 2$ (HL:HD) & $7.89 \times 10^{-2}$ & 18.12 & 8.690 & 0.964 & 0.082 & $6.25 \times 10^{-3}$ & $7.46 \times 10^{-3}$ & $9.32 \times 10^{-3}$ \\
\hline H5 & 5:1 (HL:HD) & $7.90 \times 10^{-2}$ & 16.22 & 7.409 & 0.977 & 0.070 & $4.69 \times 10^{-3}$ & $5.77 \times 10^{-3}$ & $7.50 \times 10^{-3}$ \\
\hline O1 & 1:5 (OD:OL) & $7.70 \times 10^{-3}$ & 10.36 & 3.142 & 0.969 & 0.077 & $2.37 \times 10^{-4}$ & $3.86 \times 10^{-4}$ & $7.15 \times 10^{-4}$ \\
\hline $\mathrm{O} 2$ & 2:4 (OD:OL) & $7.50 \times 10^{-3}$ & 9.944 & 3.038 & 0.960 & 0.085 & $2.44 \times 10^{-4}$ & $4.04 \times 10^{-4}$ & $7.65 \times 10^{-4}$ \\
\hline O3 & $3: 3$ (OD:OL) & $7.31 \times 10^{-3}$ & 10.70 & 3.237 & 0.981 & 0.061 & $2.38 \times 10^{-4}$ & $3.81 \times 10^{-4}$ & $6.94 \times 10^{-4}$ \\
\hline $\mathrm{O} 4$ & $4: 2$ (OD:OL) & $7.13 \times 10^{-3}$ & 10.53 & 3.223 & 0.971 & 0.073 & $2.59 \times 10^{-4}$ & $4.16 \times 10^{-4}$ & $7.59 \times 10^{-4}$ \\
\hline O5 & $5: 1$ (OD:OL) & $6.95 \times 10^{-3}$ & 11.53 & 3.556 & 0.970 & 0.075 & $2.94 \times 10^{-4}$ & $4.51 \times 10^{-4}$ & $7.79 \times 10^{-4}$ \\
\hline
\end{tabular}

Note: $C_{0}$ is stock concentration; $a$ is location parameter; $b$ is slope parameter; $R^{2}$ is coefficient of determination; RMSE is root-mean-square error; $\mathrm{EC}_{80}, \mathrm{EC}_{50}$, and $\mathrm{EC}_{30}$ are the $80 \%, 50 \%, 30 \%$-effect concentration, respectively; all the units of $\mathrm{C}_{0}, \mathrm{EC}_{80}, \mathrm{EC}_{50}$, and $\mathrm{EC}_{30}$ are $\mathrm{mol} / \mathrm{L}$.

Previous studies have demonstrated that the enantiomers of chiral pesticides have different biological toxicities [9]. In the present study, the $\mathrm{EC}_{50}$ of $\mathrm{BL}$ was 1.7 times that of $\mathrm{BD}$, and the $\mathrm{EC}_{50}$ of HD was 2.1 times that of HL. BL and BD, and HD HL showed enantioselective toxicity to AVF. While enantioselective toxicity difference was not observed for ED and EL, and OD and OL to AVF as shown in Figure 2A. Chen et al. reported the enantioselective toxicity of these four pairs of chiral lactate ILs to Scenedesmus obliquus, the $\mathrm{EC}_{50}$ value of EL was twice that of $\mathrm{ED}$ to algae, while no enantioselective toxicity difference was found for L-lactic acid and D-lactic acid [31]. Therefore, the enantioselective toxicity difference of the chiral ILs enantiomers with lactate anion should be attributed to the interaction between anions and cations.
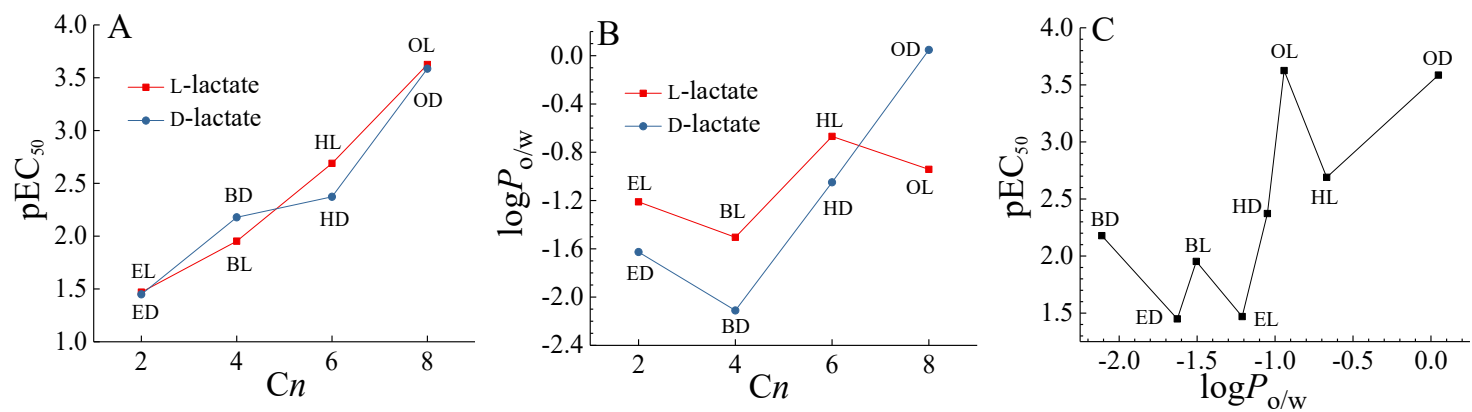

Figure 2. (A) Relationship between the toxicity $\left(\mathrm{pEC}_{50}\right)$ and the number of carbon atoms $(\mathrm{Cn})$ in the alkyl chains of the imidazolium cations of single ionic liquids (ILs), (B) relationship between the n-octanol/water partition coefficient $\left(\log P_{\mathrm{o} / \mathrm{w}}\right)$ and the $\mathrm{C} n$ of single ILs, and $(\mathbf{C})$ relationship between the $\mathrm{pEC}_{50}$ and the $\log P_{\mathrm{o} / \mathrm{w}}$ of single ILs. 
The n-octanol/water partition coefficient $\left(\log P_{\mathrm{o} / \mathrm{w}}\right)$ was an important parameter that can be used to simulate ILs diffusion from the aqueous phase to the bacterial cell membrane, and was also associated with the chemical toxicity [35]. We determined the $\log P_{\mathrm{o} / \mathrm{w}}$ of these chiral ILs as shown in Figure 2B and Table S2. It can be seen that basically the $\log P_{\mathrm{o} / \mathrm{w}}$ of L-lactate was greater than the $\log P_{\mathrm{o} / \mathrm{w}}$ of D-lactate, except for the octyl IL in the opposite order. Meanwhile, compared with ethyl, hexyl, and octyl ILs, the $\log P_{\mathrm{o} / \mathrm{w}}$ of butyl IL was the smallest, indicating that the trend of butyl IL participating in water was the largest relative to n-octanol. Normally, with the increase of the length of alkyl chain, the toxicity and lipophilicity of ILs were increased as shown in Figure 2A,B. However, the relationship between lipophilicity $\left(\log P_{\mathrm{o} / \mathrm{w}}\right)$ and toxicity (e.g., $\left.\mathrm{pEC}_{50}\right)$ was generally an inverted U-shaped, as shown in Figure 2C and the reference [36]. Therefore, there may be some balance, resulting in enantioselective toxicity difference in the imidazole lactate ILs with an intermediate number of carbon atoms. Chen et al. also observed that chiral ILs with greater carbon chain lengths no longer exhibited enantioselectivity, due to changes in the toxicity weightings of the cations [31]. Furthermore, the mechanisms of enantioselective toxicity difference of chiral ILs at the molecular and cellular levels will need further study to be elucidated [32].

ILs were different from ordinary neutral molecules. ILs can be regarded as a mixture of anions and cations. Stolte et al. proposed that the toxicity of single ILs can be calculated based on their anion and cation toxicity using the CA model [37]. Previous studies showed that the strong electrostatic interactions between an achiral cation and a chiral anion can result in the transfer, induction, and amplification of chiral information [38,39]. Such ion-pairing effects between achiral imidazolium cation and chiral lactate anion may induce the enantioselective toxicity difference.

\subsection{Enantiomer Mixture $C R C$ and $C T C$}

The mixture CRCs predicted by CA and IA together with the experimental data and the fitted curves were integrated and displayed in Figure 1. These observed CRCs can also be depicted by the Weibull function. In all cases, the $R^{2} \mathrm{~s}$ were greater than 0.85 and the RMSEs less than 0.13.

The $\mathrm{EC}_{80}, \mathrm{EC}_{50}$, and $\mathrm{EC}_{30}$ values for enantiomer mixtures are listed in Table 1. Using the $\mathrm{EC}_{x, i}$, $\mathrm{EC}_{x, \text { mix }}$, and $P_{i}$, the CTC of IL enantiomer mixtures can be obtained as shown in Table 2. According to the CTCICI method [18], at 30\%,50\%, and 80\% effect levels, the mixtures of BD and BL, HL, and HD, and $\mathrm{OD}$ and $\mathrm{OL}$ overall presented antagonistic action, except for the additive action of $\mathrm{H} 2, \mathrm{H} 3$ at $80 \%$ effect, $\mathrm{H} 1$ at 50\% effect, B4, B5, H1, O1, O2, and O4 at 30\% effect. While ED and EL mixtures presented additive action at $30 \%$ and $50 \%$ effect levels, and presented synergistic action at $80 \%$ effect level except for the additive action of the E3 mixture. Theoretically, CTC [40] was the deformation expression of CA, and the reciprocal form of the combination index [41]. Therefore, CTC only reflected the judgment result of CA on toxic interaction [42]. The advantages of CTC were simple, intuitive, quantitative, and widely used. Although in most cases, the difference between the CA and IA predictions were small for an assessment of mixture toxicity [43]. However, sometimes this difference can be too big to ignore $[44,45]$. The next step was to further study the toxic interaction of these four pairs of enantiomer mixtures from the perspective of CRC based on CA and IA in combination with CI. 
Table 2. Joint toxicity effect of enantiomer mixtures of four pairs of chiral ionic liquids to Allivibrio fischeri.

\begin{tabular}{|c|c|c|c|c|c|c|c|c|c|c|c|c|}
\hline \multirow[b]{2}{*}{ Mixtures } & \multicolumn{4}{|c|}{$\mathrm{E}=80 \%$} & \multicolumn{4}{|c|}{$E=50 \%$} & \multicolumn{4}{|c|}{$E=30 \%$} \\
\hline & СТC & $\mathrm{CTC}_{\mathrm{UL}}$ & $\mathrm{CTC}_{\mathrm{LL}}$ & Interaction & СТС & $\mathrm{CTC}_{\mathrm{UL}}$ & $\mathrm{CTC}_{\mathrm{LL}}$ & Interaction & CTC & $\mathrm{CTC}_{\mathrm{UL}}$ & $\mathrm{CTC}_{\mathrm{LL}}$ & Interaction \\
\hline E1 & 153 & 166 & 131 & synergism & 103 & 118 & 86 & additivity & 75 & 103 & 63 & additivity \\
\hline E2 & 162 & 177 & 131 & synergism & 122 & 149 & 96 & additivity & 97 & 138 & 78 & additivity \\
\hline E3 & 141 & 198 & 96 & additivity & 116 & 176 & 82 & additivity & 100 & 226 & 67 & additivity \\
\hline E4 & 158 & 179 & 131 & synergism & 118 & 193 & 73 & additivity & 93 & 166 & 60 & additivity \\
\hline E5 & 143 & 190 & 102 & synergism & 119 & 168 & 88 & additivity & 103 & 190 & 73 & additivity \\
\hline B1 & 64 & 66 & 43 & antagonism & 45 & 74 & 35 & antagonism & 34 & 48 & 29 & antagonism \\
\hline B2 & 52 & 52 & 38 & antagonism & 38 & 48 & 29 & antagonism & 29 & 45 & 28 & antagonism \\
\hline B3 & 40 & 44 & 36 & antagonism & 30 & 34 & 18 & antagonism & 23 & 41 & 17 & antagonism \\
\hline B4 & 37 & 66 & 20 & antagonism & 44 & 89 & 24 & antagonism & 50 & 201 & 25 & additivity \\
\hline B5 & 38 & 59 & 23 & antagonism & 41 & 68 & 26 & antagonism & 44 & 109 & 26 & additivity \\
\hline H1 & 43 & 69 & 10 & antagonism & 51 & 113 & 37 & additivity & 58 & 352 & 26 & additivity \\
\hline $\mathrm{H} 2$ & 38 & 124 & 13 & additivity & 34 & 48 & 23 & antagonism & 31 & 61 & 16 & antagonism \\
\hline H3 & 31 & 126 & 11 & additivity & 28 & 39 & 19 & antagonism & 25 & 49 & 20 & antagonism \\
\hline $\mathrm{H} 4$ & 44 & 46 & 21 & antagonism & 33 & 40 & 27 & antagonism & 27 & 38 & 23 & antagonism \\
\hline H5 & 49 & 50 & 39 & antagonism & 39 & 45 & 31 & antagonism & 32 & 45 & 27 & antagonism \\
\hline $\mathrm{O} 1$ & 64 & 86 & 32 & antagonism & 62 & 88 & 44 & antagonism & 62 & 112 & 41 & additivity \\
\hline $\mathrm{O} 2$ & 60 & 83 & 27 & antagonism & 61 & 90 & 40 & antagonism & 61 & 119 & 38 & additivity \\
\hline $\mathrm{O} 3$ & 67 & 81 & 44 & antagonism & 65 & 83 & 51 & antagonism & 63 & 97 & 45 & antagonism \\
\hline $\mathrm{O} 4$ & 62 & 78 & 33 & antagonism & 61 & 82 & 43 & antagonism & 59 & 100 & 40 & additivity \\
\hline O5 & 62 & 76 & 33 & antagonism & 57 & 76 & 41 & antagonism & 53 & 90 & 38 & antagonism \\
\hline
\end{tabular}

Note: CTC: co-toxicity coefficient; CTCLL: the lower limit of mixture CTC CI; CTCUL: the upper limit of mixture CTC CI

Comprehensively speaking, the predicted curves of CA and IA were above the observed CRC CI for $\mathrm{BD}$ and $\mathrm{BL}$, and HL and HD mixtures, these two pairs of enantiomers were antagonistic action. While the predicted curves of CA and IA were within the observed CRC CI for ED and EL, and OD and OL mixtures, so these two pairs of enantiomers were additive action, except that the mixtures of ED and EL were synergistic action at the $80 \%$ effect level. Single enantiomer toxicity analysis indicated that enantioselective toxicity differences were observed for BD and BL, and HL and HD mixtures, and that were not observed for ED and EL, and OD and OL mixtures. This generated a hypothesis that chiral molecules with enantioselective toxicity difference tended to produce toxicity interaction.

\subsection{Enantiomer Mixture Toxicity Assessment Based on Isobole}

Figure 3 showed the isoboles of four pairs of chiral ILs mixtures at $30 \%, 50 \%$, and $80 \%$ effect levels. In all situations, the CA isoboles were below the IA isoboles, which was the reflection of CA CRC above IA CRC. In general, the observed isoboles of the mixtures of ED and EL, and OD and OL were relatively close to the predicted isoboles of CA and IA, and the CI of the observed isoboles can basically contain the CA or IA isobole, so the two pairs of enantiomers were additive action. The only exception was ED and EL mixture presenting synergistic action at $80 \%$ effect level. In the Section 2.2, mixtures of $\mathrm{OD}$ and OL were judged to show antagonistic action. However, based on IA, these mixtures were determined to be additive. Therefore, CA and IA should be used in combination to comprehensively judge the toxicity interaction of mixtures to avoid qualitative error [18]. On the other hand, the observed isoboles of the mixtures of $\mathrm{BD}$ and $\mathrm{BL}$, and $\mathrm{HD}$ and $\mathrm{HL}$ deviated from the predicted isoboles of $\mathrm{CA}$ and IA far upward, and the CI of the observed isoboles basically cannot contain the CA or IA isobole, so these two pairs of enantiomers showed antagonistic action, and the mixture with molar ratio 1:1 generally had the largest deviation trend indicating the greatest toxic interaction. 

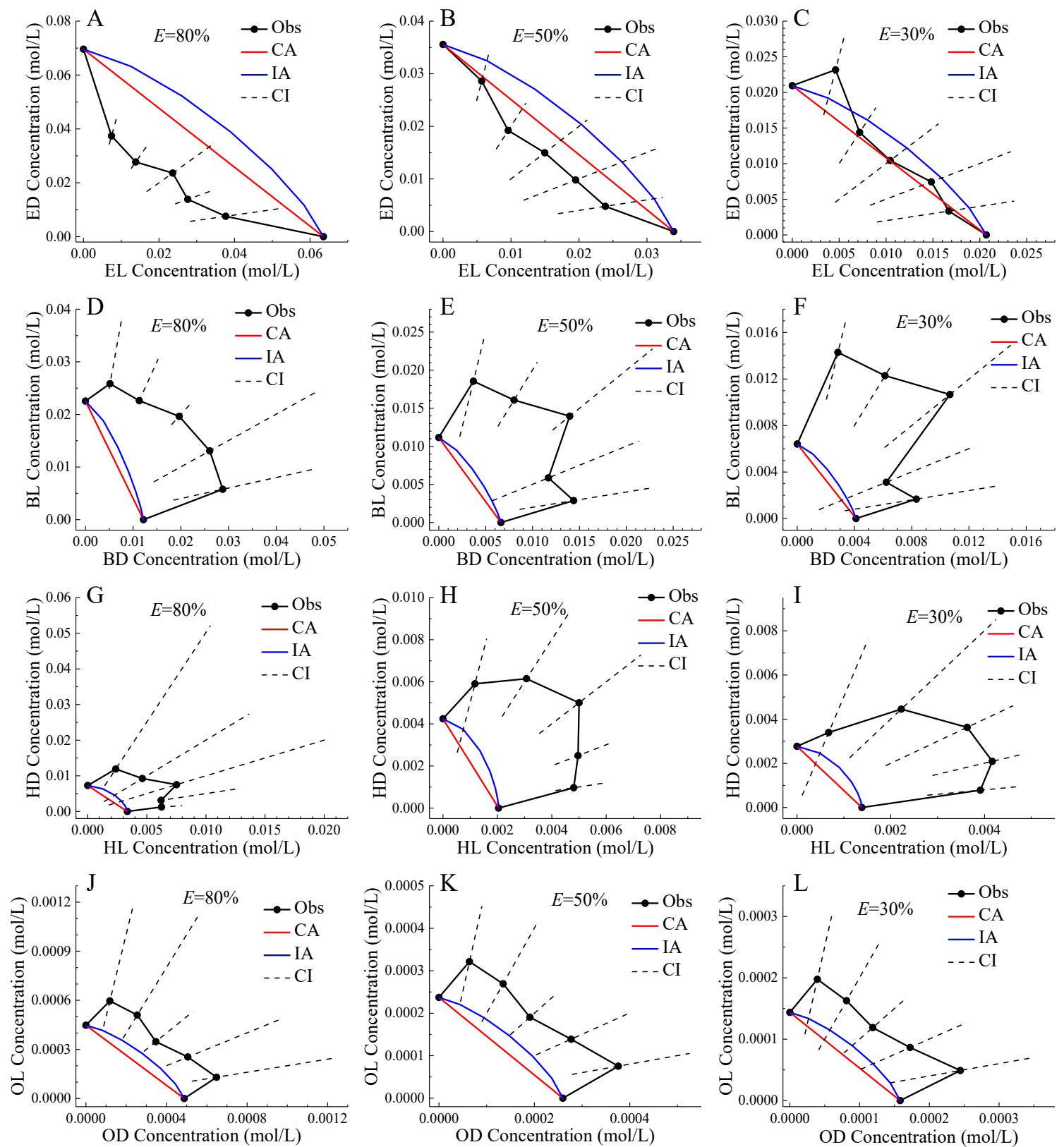

Figure 3. Isoboles of binary mixtures of enantiomers of four pairs of chiral ionic liquids to Allivibrio fischeri at $80 \%, 50 \%$, and $30 \%$ effect levels. Note: Black point: observed data; Black solid line: observed isobole; Black dashed line: confidence interval; Red line: CA isobole; Blue line: IA isobole; except for the two boundary points of the black solid line, the remaining five points in line order from left to right correspond to the enantiomer molar ratios of 1:5, 2:4 , 3:3, 4:2, and 5:1.

It was generally accepted that CA was applicable to similar acting chemicals and IA was applicable to dissimilar acting chemicals [46]. It should be more likely that enantiomers were applicable to CA, but our results indicated that IA was closer to mixture observed isobole than CA. Therefore, the question was aroused as to whether CA and IA were related to the mechanism of action (MoA). Our results supported that CA and IA were both only the additive reference models, which were not applicable to associate with the MoA. The additivity assumption was merely a working concept and did not necessarily reflect the reality [47].

In the present study, we used three methods of CTCICI, CRC, and isobole to evaluate the toxic interaction of enantiomers of chiral ILs. To date, there were few examples of evaluating enantiomeric 
mixture effects based on isobole [16]. Most of studies regarding enantiomer mixture toxicity evaluation were based on statistical judgments by comparing with the toxicity of single enantiomers [48]. The advantage of this approach was that it was simple to operate and did not require the introduction of an additive reference model. In particular, when the effect concentration of enantiomer mixture was greater than or less than the corresponding effect concentration of enantiomer components, the mixture would show antagonistic or synergistic action [49]. In theory, this was still based on the CA principle. As shown in Table 1, all the mixtures of BD and BL, HD and HL, and OD and OL at 30\%, 50\%, and $80 \%$ effect for all molar ratios, the enantiomer mixture effect concentrations $\left(\mathrm{EC}_{x, \mathrm{mix}}\right)$ were all greater than single enantiomer effect concentrations $\left(\mathrm{EC}_{x, i}\right)$, which indicated that these mixtures were theoretically antagonistic based on CA. Only the mixture of ED and EL at all molar ratios, the mixture $80 \%$-effect concentrations $\left(\mathrm{EC}_{80, \mathrm{mix}}\right.$ ) were all smaller than the enantiomer $80 \%$-effect concentrations $\left(\mathrm{EC}_{80, i}\right)$, which indicated that these mixtures were theoretically synergistic based on CA. In these cases, toxic interactions can be determined even without the use of statistical judgments, additive models, or isobole. However, when the mixture effect concentration was within or not far from the enantiomer effect concentration, it was necessary to use the additive model or isobole in combination with the CI. Comparatively speaking, isobole had the natural applicability, comprehensiveness, and accuracy in judging enantiomeric toxic interactions.

\subsection{Relationship between Mixture Toxicity and Enantiomer Concentration Proportions}

Previous studies indicated that there was biphasic relationship between the binary mixture toxicity and the concentration proportion $\left(P_{i}\right)$ of components [18]. A pair of enantiomers of chiral molecules can form the natural binary mixtures. It can be seen that in Figure 4, there were two pairs of relatively obvious U-shaped relationship between the $P_{i}$ of components and the toxicities $\left(\mathrm{pEC}_{30}, \mathrm{pEC}_{50}, \mathrm{pEC}_{80}\right)$ of mixtures of BD and BL, and HL and HD. There were two pairs of inverted U-shaped relationships between the $P_{i}$ of components and the toxicities $\left(\mathrm{pEC}_{30}, \mathrm{pEC}_{50}, \mathrm{pEC}_{80}\right)$ of mixtures of EL and $\mathrm{ED}$, and OD and OL. This phenomenon basically conformed to the climax hypothesis proposed by Lin et al. [50]. The climax hypothesis concluded that there was a climax at the equitoxic ratio when plotting the toxic ratios of individual chemicals in mixtures versus their joint effects [51].

In the present study, we deliberately designed the enantiomer mixtures according to their molar ratio, and found that the highest or lowest toxicity point was usually at the equimolar ratio, especially for the enantiomers with differential toxicity. Therefore, for the enantiomer mixture, the climax hypothesis was reduced to a new form that the highest or lowest toxicity was usually at the equimolar ratio. To show the difference, we called this type of Climax hypothesis the Crown hypothesis according to the shape of the isobole. This new improved hypothesis needed to be tested by other enantiomeric binary mixtures. 

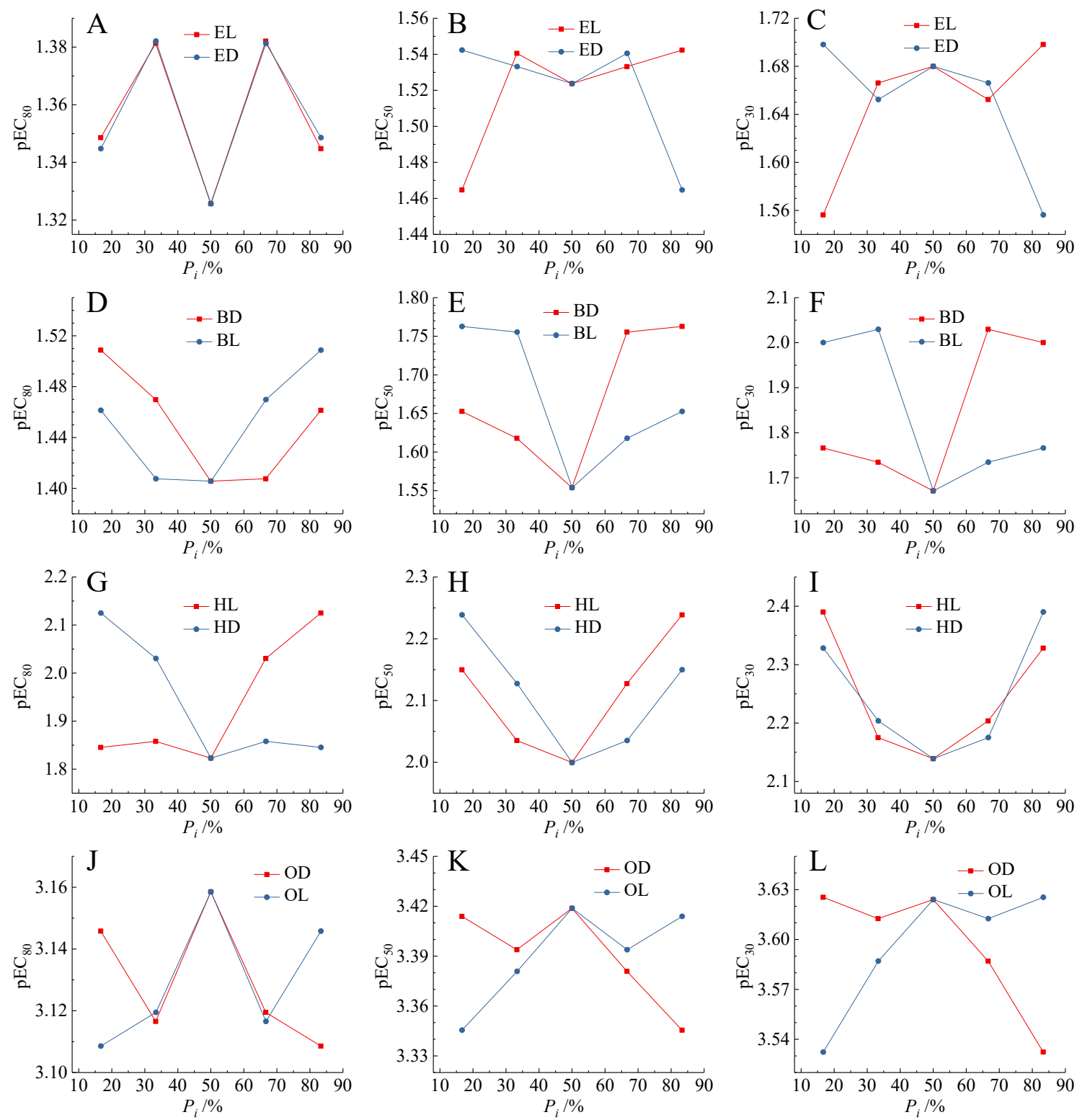

Figure 4. Relationship between the toxicity $\left(\mathrm{pEC}_{\mathrm{x}}\right)$ of enantiomeric binary mixtures and the concentration proportion $\left(P_{i}\right)$ of enantiomer components. (A-C) Mixtures of [EMIM]L-Lac and [EMIM]D-Lac; (D-F) mixtures of [BMIM]D-Lac and [BMIM]L-Lac; (G-I) mixtures of [HMIM]L-Lac and [HMIM]D-Lac; (J-L) mixtures of [OMIM]D-Lac and [OMIM]L-Lac.

\subsection{Implications}

The equimolar ratio corresponding to the greatest antagonism may reflect a certain mechanism in itself. When the ratio of enantiomers was greatly different, the one with a large proportion played a dominant role, the antagonism was also small accordingly. However, when the proportion of the two enantiomers was the same, the two had even influence and produced the greatest antagonism. More quantitative and accurate interpretation may need to apply the molecular simulation to a specific protein molecular target, such as the photobacterium luciferase.

Our results showed that the antagonistic toxicity interaction was strongest when the enantiomeric mixture was at the equimolar ratio. Raffa et al. also observed that the mixture of the tramadol enantiomers with the ratio $(-) /(+)=1 / 1$ produced the strongest synergistic action to mice for the antinociception effect expressed as inhibition of acetylcholine-induced abdominal constriction [16]. When mixtures were presented in equimolar ratio and its adjacent ratio, the maximum medicinal 
interaction can also be observed in drug synergies. In fact, the ratio-dependent synergy had also been used in pharmacology. Ribavirin and disulfiram in molar ratio 2:1 presented the maximal antibacterial synergy against methicillin-resistant Staphylococcus aureus proliferation [52]. Indacrinone was a diuretic, the (-) isomer had diuretic effect with increasing the uric acid levels in blood, while the $(+)$ isomer can promote the excretion of uric acid. It was possible to improve the therapeutic effects of indacrinone by manipulation of the enantiomer ratio, such as $(-) /(+)=1 / 4$ [53]. However, whether the equimolar ratio and its adjacent ratio presenting the maximum toxic interaction was universal required further verification.

For the ILs toxicity, it was generally accepted that the cations played a major role and were more important than anions. Our results suggested that the interaction between cations and anions may actually be more important than single ions. Our results also showed that the toxicity of octyl ILs was two orders of magnitude greater than that of ethyl ILs, while different configurations of lactate ILs had no fixed order of toxicity. To minimize the environmental risk, the chiral ILs with short alkyl chains and enantioselective toxicities should be taken into consideration [31].

\section{Materials and Methods}

\subsection{Chemicals}

The IL components included 1-ethyl-3-methylimidazolium D-lactate ([EMIM]D-Lac), 1-ethyl-3-methylimidazolium L-lactate ([EMIM]L-Lac), 1-butyl-3-methylimidazolium D-lactate ([BMIM]D-Lac), 1-butyl-3-methylimidazolium L-lactate ([BMIM]L-Lac), 1-hexyl-3-methylimidazolium D-lactate ([HMIM]D-Lac), 1-hexyl-3-methylimidazolium L-lactate ([HMIM]L-Lac), 1-octyl-3methylimidazolium D-lactate ([OMIM]D-Lac), and 1-octyl-3-methylimidazolium L-lactate ([OMIM]L-Lac). These ILs were purchased from Shanghai Chengjie Chemical Co. LTD. (Shanghai, China). The chemical structures and related information of these ILs are shown in Table 3.

The stock solutions of ILs were separately prepared through dissolving them in the deionized water and stored in a $4{ }^{\circ} \mathrm{C}$ refrigerator. The stock solutions of IL mixtures were prepared through mixing the stock solutions of individual ILs according to their concentration ratios assigned. The concentration of the stock solutions $\left(\mathrm{C}_{0}\right)$ and following diluted solutions $\left(\mathrm{C}_{1}-\mathrm{C}_{11}\right)$ of chiral ILs and their mixtures were shown in the Supplementary Materials.

Table 3. Information about chemicals used in the experiment.

\begin{tabular}{|c|c|c|c|c|c|}
\hline Chemicals & Abbreviation & $\begin{array}{l}\text { Chemical } \\
\text { Formula }\end{array}$ & $\begin{array}{l}\text { Molecular } \\
\text { Structure }\end{array}$ & Purity & $\begin{array}{c}\text { Molecular } \\
\text { Weight }\end{array}$ \\
\hline [EMIM]D-Lac & ED & $\mathrm{C}_{9} \mathrm{H}_{16} \mathrm{~N}_{2} \mathrm{O}_{3}$ & & $98 \%$ & 200.23 \\
\hline [EMIM]L-Lac & EL & $\mathrm{C}_{9} \mathrm{H}_{16} \mathrm{~N}_{2} \mathrm{O}_{3}$ & & $98 \%$ & 200.23 \\
\hline [BMIM]D-Lac & $\mathrm{BD}$ & $\mathrm{C}_{11} \mathrm{H}_{20} \mathrm{~N}_{2} \mathrm{O}_{3}$ & & $98 \%$ & 228.29 \\
\hline [BMIM]L-Lac & BL & $\mathrm{C}_{11} \mathrm{H}_{20} \mathrm{~N}_{2} \mathrm{O}_{3}$ & & $98 \%$ & 228.29 \\
\hline
\end{tabular}


Table 3. Cont.

\begin{tabular}{lccccc}
\hline Chemicals & Abbreviation & $\begin{array}{c}\text { Chemical } \\
\text { Formula }\end{array}$ & $\begin{array}{c}\text { Molecular } \\
\text { Structure }\end{array}$ & Pority \\
Weight
\end{tabular}

\subsection{Photobacterium Toxicity Test}

The photobacterium Aliivibrio fischeri (Strain number 1H00019) was purchased from Marine Culture Collection of China (MCCC). The culture medium consisted of $1 \mathrm{~g} \mathrm{KH}{ }_{2} \mathrm{PO}_{4}, 4.7 \mathrm{~g} \mathrm{Na}_{2} \mathrm{HPO}_{4} \cdot 12 \mathrm{H}_{2} \mathrm{O}$, $0.3 \mathrm{~g} \mathrm{MgSO}_{4} \cdot 7 \mathrm{H}_{2} \mathrm{O}, 0.5 \mathrm{~g}\left(\mathrm{NH}_{4}\right)_{2} \mathrm{HPO}_{4}, 30 \mathrm{~g} \mathrm{NaCl}, 5.0 \mathrm{~g}$ yeast extract powder, $5.0 \mathrm{~g}$ tryptone, $3.0 \mathrm{~g}$ glycerin, and $1000 \mathrm{~mL}$ water, and was adjusted to $\mathrm{pH} 6.7 \pm 0.3$. The AVF was grown in the culture medium at $22 \pm 1{ }^{\circ} \mathrm{C}$ by shaking $(120 \mathrm{r} / \mathrm{min})$ for $8-12 \mathrm{~h}$ during the logarithmic growth phase until the relative light unit reached $1 \times 10^{6}$ for the toxicity test.

The toxicities of single ILs and their mixtures were expressed as an inhibition of the AVF luminescence. According to the methods of MTA [54], IL chemicals and their mixtures with 11 concentration series in eight repeats and eight controls were arranged in a microplate. First, $100 \mu \mathrm{L}$ water was added to eight wells in the twelfth column as blank controls, $100 \mu \mathrm{L}$ of the solutions of IL chemicals, and their mixtures with 11 gradient concentrations according to a geometric dilution factors of 0.5 were added to the wells from the first to the eleventh column. Then, $100 \mu \mathrm{L}$ AVF suspension was added into each well to reach the final volume of $200 \mu \mathrm{L}$. The relative light units (RLUs) of the AVF system exposed to single ILs and their mixtures were determined on Synergy 2 Multi-Mode Microplate Readers (BioTek Instruments, Winooski, VT, USA) with a 96-well white flat bottom microplate (Corning 3917) after $30 \mathrm{~min}$ of exposure at $26 \pm 1{ }^{\circ} \mathrm{C}$.

The inhibitive effect ( $E$ of $x \%$ ) of individual ILs and their mixtures was calculated using Equation (1). The CRCs were fitted by Weibull function shown in Equation (2) using least squares method [55]. The goodness of fit of statistical models was evaluated by $R^{2}$ and RMSE. As a quantitative measure of the uncertainty, the observation-based $95 \%$ CI was determined [56].

$$
\begin{gathered}
E=1-\frac{L}{L_{0}} \\
E=1-\exp \left(-\exp \left(a+b \times \log _{10}(C)\right)\right)
\end{gathered}
$$

where $L_{0}$ is the average of RLUs of controls, $L$ is the average of RLUs of treatments, $E$ is inhibitive effect of AVF luminescence, $C$ is chemical concentration, $a$ is location parameter, and $b$ is slope parameter.

\subsection{Experimental Design and Toxicity Evaluation of Mixtures}

The five binary mixtures of each pair of enantiomers were designed using the EquRay design [57], every two enantiomers were mixed according to molar ratios of 1:5, 2:4, 3:3, 4:2, and 5:1. The molar ratio 
was chosen instead of the toxic unit ratio to construct the racemic mixture and to increase the generality of the experimental design.

The models of CA shown in Equation (3) and IA shown in Equation (4) were used to predict the mixture effect concentration $\left(\mathrm{EC}_{x, \mathrm{mix}}\right)$ corresponding to the mixture $\mathrm{x} \%$ effect, and the predicted CRC of the mixture was also presented [58]. The predicted $\mathrm{EC}_{x \text {, mix }}$ was multiplied by the enantiomer concentration fraction $\left(P_{i}\right)$ to obtain the two partial concentrations which formed a point in the two-dimensional Cartesian coordinates. These points were connected to form the mixture predicted isobole. When the CIs of mixture observed isobole were containing, above, or below the mixture predicted isobole, the mixture was judged to present additive, antagonistic, or synergistic action, respectively.

For CRC, when the mixture predicted CRC was located within the CIs of mixture observed CRC, the mixture presented additive action. When the mixture predicted CRC was located above or below the mixture observed CRC CI, the mixture presented antagonistic or synergistic action, respectively.

At the single effect point level, the toxic interactions of mixtures were evaluated using the components $\mathrm{EC}_{x, i}$, and mixture observed $\mathrm{EC}_{x, \text { mix }}$ and its $95 \% \mathrm{CI}$ according to the CTCICI method developed recently [18]. The CTC were computed using Equation (5). When 100 was included in the CI of mixture CTC, the mixture presented additive action. When the CI of mixture CTC was greater or smaller than 100, the mixture presented synergistic or antagonistic action, respectively.

$$
\begin{gathered}
\mathrm{EC}_{x, \text { mix }}=1 / \sum_{i=1}^{n}\left(P_{i} / \mathrm{EC}_{x, i}\right) \\
x \%=1-\prod_{i=1}^{n}\left(1-F_{i}\left(P_{i} \times \mathrm{EC}_{x, \text { mix }}\right)\right) \\
\mathrm{CTC}=100 /\left(\mathrm{EC}_{x, \text { mix }} \times \sum_{i=1}^{n}\left(P_{i} / \mathrm{EC}_{x, i}\right)\right)
\end{gathered}
$$

where $n$ is the number of mixture components, $E C_{x, i}$ is the concentration of $i$ th component eliciting the $x \%$ effect, $E C_{x \text {,mix }}$ is the concentration of a mixture eliciting the $x \%$ effect, $P_{i}$ is the concentration proportion of $i$ th component in a mixture, $F_{i}$ is individual concentration-response functions, CTC is co-toxicity coefficient.

\section{Conclusions}

The toxicities of the four pairs of chiral ionic liquids (ILs) to Allivibrio fischeri were explored. Interestingly, two pairs of chiral ILs showed enantioselective toxicity difference, while the other two pairs of chiral ILs showed no enantioselective toxicity difference. Thereinto, the enantiomer mixtures of two pairs of chiral ILs with enantioselective toxicity difference presented antagonistic action, that without enantioselective toxicity difference overall presented additive action. Moreover, the greatest toxic interaction occurred at the enantiomer molar ratio 1:1. These results may have important implications and practical applications for chiral molecules in toxicology, pharmacology, environmental science, pesticide science, and other research fields.

Supplementary Materials: Supplementary materials can be found at http://www.mdpi.com/1422-0067/20/24/ 6163/s1.

Author Contributions: Conceptualization, H.G.; Investigation, H.G. and M.Z.; Writing—original draft, H.G.; Writing-review and editing, D.L., M.W., C.D., Y.W., Z.Z. and S.W.

Funding: This work was financially supported by the National Natural Science Foundation of China (No. 21675138), the National Science and Technology Major Project of the Ministry of Science and Technology of China (No. 2016YFD0201203), the Key Science and Technology Projects of Hainan Province (No. ZDXM20130043), the Special Fund for the Construction of Modern Agricultural Industrial Technology System (No. CARS-31-13), 
and the Scientific and Technological Innovation Project of Chinese Academy of Agricultural Sciences (No. CAAS-XTCX20190025-04).

Conflicts of Interest: The authors declare no conflict of interest.

\section{References}

1. Liu, W.; Gan, J.; Schlenk, D.; Jury, W.A. Enantioselectivity in environmental safety of current chiral insecticides. Proc. Natl. Acad. Sci. USA 2005, 102, 701-706. [CrossRef] [PubMed]

2. Nguyen, L.; He, H.; Pham-Huy, C. Chiral drugs: an overview. Int. J. Biomed. Sci. 2006, 2, 85-100. [PubMed]

3. Lee, S.T.; Green, B.T.; Welch, K.D.; Pfister, J.A.; Panter, K.E. Stereoselective potencies and relative toxicities of coniine enantiomers. Chem. Res. Toxicol. 2008, 21, 2061-2064. [CrossRef] [PubMed]

4. Masurel, D.; Houghton, P.J.; Young, C.L.; Wainer, I.W. Efficacy, toxicity, pharmacokinetics, and in vitro metabolism of the enantiomers of ifosfamide in mice. Cancer Res. 1990, 50, 252-255. [PubMed]

5. Zhu, Y.; Liu, W.; Qi, S.; Wang, H.; Wang, Y.; Deng, G.; Zhang, Y.; Li, S.; Ma, C.; Wang, Y.; et al. Stereoselective glucuronidation metabolism, pharmacokinetics, anti-amnesic pharmacodynamics, and toxic properties of vasicine enantiomers in vitro and in vivo. Eur. J. Pharm. Sci. 2018, 123, 459-474. [CrossRef] [PubMed]

6. Oliva-Damaso, E.; Oliva-Damaso, N.; Rodriguez-Esparragon, F.; Payan, J.; Baamonde-Laborda, E.; Gonzalez-Cabrera, F.; Santana-Estupiñan, R.; Rodriguez-Perez, C.J. Asymmetric (ADMA) and symmetric (SDMA) dimethylarginines in chronic kidney disease: a clinical approach. Int. J. Mol. Sci. 2019, $20,3668$. [CrossRef]

7. Neale, P.A.; Branch, A.; Khan, S.J.; Leusch, F.D.L. Evaluating the enantiospecific differences of non-steroidal anti-inflammatory drugs (NSAIDs) using an ecotoxicity bioassay test battery. Sci. Total Environ. 2019, 694, 133659. [CrossRef]

8. Chen, Z.; Yao, X.; Dong, F.; Duan, H.; Shao, X.; Chen, X.; Yang, T.; Wang, G.; Zheng, Y. Ecological toxicity reduction of dinotefuran to honeybee: New perspective from an enantiomeric level. Environ. Int. 2019, 130, 104854. [CrossRef]

9. Pan, X.; Cheng, Y.; Dong, F.; Liu, N.; Xu, J.; Liu, X.; Wu, X.; Zheng, Y. Stereoselective bioactivity, acute toxicity and dissipation in typical paddy soils of the chiral fungicide propiconazole. J. Hazard. Mater. 2018, 359, 194-202. [CrossRef]

10. Di, S.; Cang, T.; Qi, P.; Wang, X.; Xu, M.; Wang, Z.; Xu, H.; Wang, Q.; Wang, X. A systemic study of enantioselectivity of isocarbophos in rice cultivation: Enantioselective bioactivity, toxicity, and environmental fate. J. Hazard. Mater. 2019, 375, 305-311. [CrossRef]

11. Xie, J.; Zhao, L.; Liu, K.; Guo, F.; Gao, L.; Liu, W. Activity, toxicity, molecular docking, and environmental effects of three imidazolinone herbicides enantiomers. Sci. Total Environ. 2018, 622-623, 594-602. [CrossRef] [PubMed]

12. Chen, H.; Shen, C.; Chen, Z.; Ali, B.A.; Wen, Y. Dichlorprop induced structural changes of LHCII chiral macroaggregates associated with enantioselective toxicity to Scnedesmus obliquus. Aquat. Toxicol. 2019, 206, 54-60. [CrossRef] [PubMed]

13. Zhang, P.; Wang, S.; He, Y.; Xu, Y.; Shi, D.; Yang, F.; Yu, W.; Zhu, W.; He, L. Identifying metabolic perturbations and toxic effects of rac-metalaxyl and metalaxyl-M in mice using integrative NMR and UPLC-MS/MS based metabolomics. Int. J. Mol. Sci. 2019, 20, 5457. [CrossRef] [PubMed]

14. Ramírez, D.; Caballero, J. Is it reliable to use common molecular docking methods for comparing the binding affinities of enantiomer pairs for their protein target? Int. J. Mol. Sci. 2016, 17, 525. [CrossRef]

15. Lin, K.; Liu, W.; Li, L.; Gan, J. Single and joint acute toxicity of isocarbophos enantiomers to Daphnia magna. J. Agric. Food Chem. 2008, 56, 4273-4277. [CrossRef]

16. Raffa, R.B.; Friderichs, E.; Reimann, W.; Shank, R.P.; Codd, E.E.; Vaught, J.L.; Jacoby, H.I.; Selve, N. Complementary and synergistic antinociceptive interaction between the enantiomers of tramadol. J. Pharmacol. Exp. Ther. 1993, 267, 331-340.

17. Hinfray, N.; Tebby, C.; Piccini, B.; Bourgine, G.; Aït-Aïssa, S.; Porcher, J.M.; Pakdel, F.; Brion, F. Mixture concentration-response modeling reveals antagonistic effects of estradiol and genistein in combination on brain aromatase gene (cyp19a1b) in zebrafish. Int. J. Mol. Sci. 2018, 19, 1047. [CrossRef] 
18. Ge, H.L.; Tao, S.S.; Zhou, M.; Han, B.J.; Yuan, H.Q. Integrative assessment of mixture toxicity of three ionic liquids on acetylcholinesterase using a progressive approach from 1D point, 2D curve, to 3D surface. Int. J. Mol. Sci. 2019, 20, 5330. [CrossRef]

19. Pham, T.P.T.; Cho, C.W.; Yun, Y.S. Environmental fate and toxicity of ionic liquids: A review. Water Res. 2010, 44, 352-372. [CrossRef]

20. Ge, H.L.; Liu, S.S.; Su, B.X.; Zhu, X.W. Two-stage prediction of the effects of imidazolium and pyridinium ionic liquid mixtures on luciferase. Molecules 2014, 19, 6877-6890. [CrossRef]

21. Baudequin, C.; Baudoux, J.; Levillain, J.; Cahard, D.; Gaumont, A.C.; Plaquevent, J.C. Ionic liquids and chirality: opportunities and challenges. Tetrahedron Asymmetry 2003, 14, 3081-3093. [CrossRef]

22. Sedghamiz, T.; Bahrami, M. Chiral ionic liquid interface as a chiral selector for recognition of propranolol enantiomers: A molecular dynamics simulations study. J. Mol. Liq. 2019, 292, 111441. [CrossRef]

23. Yu, S.F.; Lindeman, S.; Tran, C.D. Chiral ionic liquids: synthesis, properties, and enantiomeric recognition. J. Org. Chem. 2008, 73, 2576-2591. [CrossRef] [PubMed]

24. Luo, Y.R.; Wang, S.H.; Yun, M.X.; Li, X.Y.; Wang, J.J.; Sun, Z.J. The toxic effects of ionic liquids on the activities of acetylcholinesterase and cellulase in earthworms. Chemosphere 2009, 77, 313-318. [CrossRef]

25. Ranke, J.; Molter, K.; Stock, F.; Bottin-Weber, U.; Poczobutt, J.; Hoffmann, J.; Ondruschka, B.; Filser, J.; Jastorff, B. Biological effects of imidazolium ionic liquids with varying chain lengths in acute Vibrio fischeri and WST-1 cell viability assays. Ecotoxicol. Environ. Saf. 2004, 58, 396-404. [CrossRef]

26. Cho, C.W.; Jeon, Y.C.; Pham, T.P.T.; Vijayaraghavan, K.; Yun, Y.S. The ecotoxicity of ionic liquids and traditional organic solvents on microalga Selenastrum capricornutum. Ecotoxicol. Environ. Saf. 2008, 71, 166-171. [CrossRef]

27. Kumar, R.A.; Papaiconomou, N.; Lee, J.M.; Salminen, J.; Clark, D.S.; Prausnitz, J.M. In vitro cytotoxicities of ionic liquids: effect of cation rings, functional groups, and anions. Environ. Toxicol. 2009, 24, 388-395. [CrossRef]

28. Matzke, M.; Stolte, S.; Arning, U.; Uebers, U.; Filser, J. Imidazolium based ionic liquids in soils: effects of the side chain length on wheat (Triticum aestivum) and cress (Lepidium sativum) as affected by different clays and organic matter. Green Chem. 2008, 10, 584-591. [CrossRef]

29. Costello, D.M.; Brown, L.M.; Lamberti, G.A. Acute toxic effects of ionic liquids on zebra mussel (Dreissena polymorpha) survival and feeding. Green Chem. 2009, 11, 548-553. [CrossRef]

30. Pretti, C.; Chiappe, C.; Baldetti, I.; Brunini, S.; Monni, G.; Intorre, L. Acute toxicity of ionic liquids for three freshwater organisms: Pseudokirchneriella subcapitata, Daphnia magna and Danio rerio. Ecotoxicol. Environ. Saf. 2009, 72, 1170-1176. [CrossRef]

31. Chen, H.; Zou, Y.; Zhang, L.; Wen, Y.; Liu, W. Enantioselective toxicities of chiral ionic liquids 1-alkyl-3-methylimidazolium lactate to aquatic algae. Aquat. Toxicol. 2014, 154, 114-120. [CrossRef] [PubMed]

32. Liu, H.; Wu, J.; Zhang, X.; Xia, Y.; Li, Y.; Du, S. Enantioselective oxidative stress caused by chiral ionic liquids forms of 1-alkyl-3-methyl imidazolium tartrate on Scenedesmus obliquus. Sci. Total Environ. 2017, 595, 819-827. [CrossRef] [PubMed]

33. John, R.P.; Nampoothiri, K.M.; Pandey, A. Fermentative production of lactic acid from biomass: An overview on process developments and future perspectives. Appl. Microbiol. Biotechnol. 2007, 74, 524-534. [CrossRef] [PubMed]

34. Stock, F.; Hoffmann, J.; Ranke, J.; Störmann, R.; Ondruschka, B.; Jastorff, B. Effects of ionic liquids on the acetylcholinesterase-A structure-activity relationship consideration. Green Chem. 2004, 6, 286-290. [CrossRef]

35. Lin, Z.; Yu, H.; Gao, S.; Cheng, J.; Wang, L. Development of the fragment constant method for estimating the partition coefficients of nonionic organic mixtures. Arch. Environ. Contam. Toxicol. 2001, 41, 255-260.

36. Zhu, X.W.; Liu, S.S.; Ge, H.L.; Liu, Y. Comparison between the short-term and the long-term toxicity of six triazine herbicides on photobacteria Q67. Water Res. 2009, 43, 1731-1739. [CrossRef]

37. Stolte, S.; Arning, J.; Bottin-Weber, U.; Matzke, M.; Stock, F.; Thiele, K.; Uerdingen, M.; Welz-Biermann, U.; Jastorff, B.; Ranke, J. Anion effects on the cytotoxicity of ionic liquids. Green Chem. 2006, 8, 621-629. [CrossRef]

38. Schulz, P.S.; Muller, N.; Bosmann, A.; Wasserscheid, P. Effective chirality transfer in ionic liquids through ion-pairing effects. Angew. Chem. Int. Ed. 2007, 46, 1293-1295. [CrossRef]

39. Zeng, L.X.; He, Y.J.; Dai, Z.F.; Wang, J.; Cao, Q.; Zhang, Y.L. Chiral induction, memory, and amplification in porphyrin homoaggregates based on electrostatic interactions. Chem. Phys. Chem. 2009, 10, 954-962. [CrossRef] 
40. Sun, Y.P.; Johnson, E.R. Analysis of joint action of insecticides against house flies. J. Econ. Entomol. 1960, 53, 887-892. [CrossRef]

41. Liu, L.; Liu, S.S.; Yu, M.; Chen, F. Application of the combination index integrated with confidence intervals to study the toxicological interactions of antibiotics and pesticides in Vibrio qinghaiensis sp.-Q67. Environ. Toxicol. Pharmacol. 2015, 39, 447-456. [CrossRef]

42. Chen, J.; Jiang, W.; Hu, H.; Ma, X.; Li, Q.; Song, X.; Ren, X.; Ma, Y. Joint toxicity of methoxyfenozide and lufenuron on larvae of Spodoptera exigua Hübner (Lepidoptera: Noctuidae). J. Asia Pac. Entomol. 2019, 22, 795-801. [CrossRef]

43. Cedergreen, N.; Streibig, J.C. Can the choice of endpoint lead to contradictory results of mixture-toxicity experiments? Environ. Toxicol. Chem. 2005, 24, 1676-1683. [CrossRef]

44. Backhaus, T.; Scholze, M.; Grimme, L.H. The single substance and mixture toxicity of quinolones to the bioluminescent bacterium Vibrio fischeri. Aquat. Toxicol. 2000, 49, 49-61. [CrossRef]

45. Grote, M.; Brack, W.; Walter, H.A.; Altenburger, R. Light as a confounding factor for toxicity assessment of complex contaminated sediments. Environ. Toxicol. Chem. 2005, 24, 3143-3152. [CrossRef] [PubMed]

46. Faust, M.; Altenburger, R.; Backhaus, T.; Blanck, H.; Boedeker, W.; Gramatica, P.; Hamer, V.; Scholze, M.; Vighi, M.; Grimme, L.H. Predicting the joint algal toxicity of multi-component s-triazine mixtures at low-effect concentrations of individual toxicants. Aquat. Toxicol. 2001, 56, 13-32. [CrossRef]

47. Altenburger, R.; Nendza, M.; Schuurmann, G. Mixture toxicity and its modeling by quantitative structure-activity relationships. Environ. Toxicol. Chem. 2003, 22, 1900-1915. [CrossRef]

48. Cheng, C.; Huang, L.; Diao, J.; Zhou, Z. Enantioselective toxic effects and degradation of myclobutanil enantiomers in Scenedesmus obliquus. Chirality 2013, 25, 858-864. [CrossRef]

49. Ge, H.L.; Liu, S.S.; Su, B.X.; Xu, Z. Mathematical derivation of concentration addition, independent action and effect summation models. Appl. Mech. Mater. 2013, 361-363, 1054-1057. [CrossRef]

50. Lin, Z.; Zhong, P.; Kong, D.; Yin, K.; Cai, Z. The ratios of individual chemicals in a mixture determine the degree of joint effect: the climax hypothesis. Arch. Environ. Contam. Toxicol. 2005, 49, 1-8. [CrossRef]

51. Tian, D.Y.; Lin, Z.F.; Yin, D.Q. Quantitative structure activity relationships (QSAR) for binary mixtures at non-equitoxic ratios based on toxic ratios-effects curves. Dose Response 2012, 11, 255-269. [CrossRef] [PubMed]

52. Lehár, J.; Krueger, A.S.; Avery, W.; Heilbut, A.M.; Johansen, L.M.; Price, E.R.; Rickles, R.J.; Short, G.F., III; Staunton, J.E.; Jin, X.; et al. Synergistic drug combinations tend to improve therapeutically relevant selectivity. Nat. Biotechnol. 2009, 27, 659-666. [CrossRef] [PubMed]

53. Tobert, J.A.; Cirillo, V.J.; Hitzenberger, G.; James, I.; Pryor, J.; Cook, T.; Buntinx, A.; Holmes, I.B.; Lutterbeck, P.M. Enhancement of uricosuric properties of indacrinone by manipulation of the enantiomer ratio. Clin. Pharmacol. Ther. 1981, 29, 344-350. [CrossRef] [PubMed]

54. Zhang, Y.H.; Liu, S.S.; Song, X.Q.; Ge, H.L. Prediction for the mixture toxicity of six organophosphorus pesticides to the luminescent bacterium Q67. Ecotoxicol. Environ. Saf. 2008, 71, 880-888. [CrossRef] [PubMed]

55. Scholze, M.; Boedeker, W.; Faust, M.; Backhaus, T.; Altenburger, R.; Grimme, L.H. A general best-fit method for concentration-response curves and the estimation of low-effect concentrations. Environ. Toxicol. Chem. 2001, 20, 448-457. [CrossRef]

56. Zhu, X.W.; Liu, S.S.; Ge, H.L.; Liu, Y. Comparison between two confidence intervals of dose-response relationships. China Environ. Sci. 2009, 29, 113-117.

57. Dou, R.N.; Liu, S.S.; Mo, L.Y.; Liu, H.L.; Deng, F.C. A novel direct equipartition ray design (EquRay) procedure for toxicity interaction between ionic liquid and dichlorvos. Environ. Sci. Pollut. Res. 2011, 18, 734-742. [CrossRef]

58. Faust, M.; Altenburger, R.; Backhaus, T.; Blanck, H.; Boedeker, W.; Gramatica, P.; Hamer, V.; Scholze, M.; Vighi, M.; Grimme, L.H. Joint algal toxicity of 16 dissimilarly acting chemicals is predictable by the concept of independent action. Aquat. Toxicol. 2003, 63, 43-63. [CrossRef]

(C) 2019 by the authors. Licensee MDPI, Basel, Switzerland. This article is an open access article distributed under the terms and conditions of the Creative Commons Attribution (CC BY) license (http://creativecommons.org/licenses/by/4.0/). 